\section{THEORÍA}

REVISTA DEL COLEGIO DE FILOSOFÍA
NÚMERO 41 | DICIEMBRE 2021 - MAYO 2022 | 72-93

DOI: $10.22201 /$ ffyl.16656415p.2021.41.1451

Recibido: 15-12- 2020 | Aceptado: 9-06-2021

\title{
El CONCEPTO de CUERPo en HeIdegger y Zubiri: estudio COMPARATivo
}

\author{
The Concept of the Body in Heidegger and Zubiri: Comparative Study
}

\author{
Mauricio ZEPEDA \\ Universidad Nacional Autónoma de México | México \\ Contacto: maalzesa@hotmail.com
}

\section{Resumen}

El objetivo de este trabajo es comparar el concepto de cuerpo en Heidegger y Zubiri. Para ello, expondré la idea de cuerpo en ambos autores. Heidegger no trató unitariamente al cuerpo; Zubiri, sí. Esto implica reconstruir el concepto de cuerpo en el primero. Lo haré periodizando su doctrina según tres épocas: la correspondiente a Ser y tiempo, a Los conceptos fundamentales de la metafísica y a Seminarios de Zollikon. Dichas épocas las relaciono con tres conceptos: cuerpo (Leib), organismo (Organismus) y soma (Soma), respectivamente. Para Heidegger, el cuerpo, en el marco de la espacialización existencial, es un corporar codeterminado fundado en el ser-en-elmundo del Dasein. En el caso de Zubiri, basta con exponer los conceptos más importantes sobre el cuerpo. Esto es, la constructividad y lo psicorgánico. La constructividad implica desarrollar la idea de realidad y sustantividad. Por otra parte, lo psicorgánico es el punto de partida de Zubiri para pensar al cuerpo. Lo psicorgánico posee un momento de corporeidad en el cual se despliega la función somática como actualidad presencial. Una vez hecha la exposición de ambos autores, haré, a modo de conclusión, una comparación de sus propuestas, donde destacaré las similitudes y diferencias. Además, haré una evaluación crítica, donde argumentaré el mayor éxito de la propuesta zubiriana, así como elementos sobre el cuerpo que ambos autores omitieron.

Palabras clave: cuerpo, corporalidad, corporeidad, organismo, metafísica, ontología

\begin{abstract}
The goal of this work is to compare the concept of the body in Heidegger and Zubiri. To do this, I will present the idea of the body in both authors. Heidegger did not treat the body unitarily while Zubiri did. This implies reconstructing the concept of the body in Heidegger. I will be starting to periodize his doctrine in three epochs: Being and Time, The Fundamental Concepts of Metaphysics, and Zollikon Seminars. I relate these epochs to three concepts: body (Leib), organism (Organismus), and soma (Soma). For Heidegger, the body in the conceptual framework of an existential spatialization is a codetermined body founded on the being-in-the-world of Dasein. In the case of Zubiri, it is enough to expose the most important concepts about the body. That is, constructiveness and the psycho-organic. Constructiveness implies developing the idea of reality and substantivity, but the psycho-organic is Zubiris starting point to think about the body. The psycho-organic possesses a moment of embodiment, in which the somatic function unfolds as present actuality. Once the presentation of both authors is done, I will make a conclusion and a comparison between both proposals in which I will highlight their similarities and differences. I will conclude with a critical evaluation, in which I will argue the greatest success of Zubiri's proposal, as well as the elements regarding the body that both authors omitted.
\end{abstract}

Keywords: body, embodying, organism, metaphysics, ontology 


\section{Introducción}

unque marginalmente, Heidegger se preocupó por el problema del cuerpo en
Ser y tiempo. De hecho, lo sitúa como un aspecto fundamental en la estructura
y comprensión del Dasein. ${ }^{1}$ Es llamativo que Heidegger no detallase al cuerpo, ya que, siendo un autor afecto a las etimologías, parece patente la relación entre "cuerpo" (Leib), "persona" (Leibhaftig) y "vida" (Leben). De cualquier modo, el reconocimiento que Heidegger concedió al cuerpo puede comprobarse en dicha obra, porque señala cómo debe investigarse a la corporalidad; prescribe las directrices para su abordaje radical. Heidegger no desarrolló el problema del cuerpo en Ser y tiempo, pero sí ahondó en él en los seminarios recogidos en Seminarios de Zollikon. Y, de un modo u otro, lo aludió en las lecciones que conforman el libro Los conceptos fundamentales de la metafísica. ${ }^{2}$ Es insostenible decir que Heidegger no reflexionó al cuerpo.

Zubiri, por otra parte, estudió con Husserl y asistió a las lecciones de Los conceptos fundamentales. Familiarizado con la fenomenología y el análisis ontológico, tomó distancia, sin embargo, para delinear su propuesta metafísica: el realismo constructo. Zubiri asistió a aquellas lecciones, pero no a los seminarios de Zollikon, los cuales se publicaron después de su muerte. Lo interesante es que, pese a que Zubiri no asistió a los seminarios de Zollikon y de que Heidegger no leyó a Zubiri, las tesis y conceptos de ambos son muy similares. No obstante, sus tratamientos son distintos y hasta opuestos, lo cual se hace evidente en el aspecto central del asunto: lo psicosomático. Es decir, la conexión entre psique y soma de cara a la unidad humana, pues es desde

1 Es notable que casi no haya artículo - en francés o español, al menos- sobre Heidegger y el cuerpo que no miente al célebre "reproche" que Sartre habría dirigido a Heidegger por sólo hablar "seis líneas" sobre el cuerpo en Ser y tiempo. No obstante, es difícil ubicar este presunto reproche. No parece estar en la obra de Sartre y, sin duda, no está en El ser y la nada, donde critica al Dasein heideggeriano por asexuado (Sartre, 1993: 407). Parece ser que quien difundió ese reproche fue Boss. Este, en su correspondencia con Heidegger, dice: "Otros retomaron el reproche de Jean Paul Sartre, el cual se sorprendió de que usted haya escrito solamente seis líneas acerca del cuerpo en todo Ser y tiempo". Heidegger respondió: "El reproche de Sartre solamente puedo confrontarlo con la afirmación de que lo corporal es lo más difícil y que en aquel entonces no tenía más que decir al respecto" (Heidegger, 2007b: 311). Fuera de esta cita específica, no parece haber otro registro; no parece que Sartre lo haya dicho. Es como si Boss, sin quererlo, hubiese popularizado hasta el lugar común la crítica más recurrente a Heidegger. Y es más notable aún que esta crítica proceda del libro donde Heidegger se pronuncia sobre el cuerpo. Es decir, el reproche es un tópico obsoleto, válido únicamente en la época en que se escribió Ser y tiempo.

2 En adelante, Los conceptos fundamentales. 
ella -la unidad- que conceptuaron al cuerpo. ${ }^{3}$ Toda similitud y diferencia está enmarcada en sendos tratamientos: el análisis ontológico y el realismo constructo.

A todo esto, no debe perderse de vista que el concepto de cuerpo en Heidegger está desperdigado a lo largo de su obra; Zubiri, en cambio, lo expone monográficamente en El hombre y su cuerpo. Es preciso establecer en cada caso una metodología, ya que se expondrá una doctrina reconstruida en Heidegger y se enfatizarán, a partir de aquella reconstrucción, ciertos elementos de la doctrina zubiriana. Sin embargo, la reconstrucción es ya una propuesta hermenéutica. Es un modo de leer a Heidegger que implica explicitar sus límites. Hay que responder, en primera instancia, en qué sentido puede hablarse de una doctrina del cuerpo heideggeriana. Una vez hecho tal, revisaré cómo conceptuó Heidegger - a la luz de dicha propuesta hermenéutica- al cuerpo. Como se verá, no es lo mismo exponer las tesis heideggerianas a la luz del contexto en el que están enunciadas que a luz de una doctrina hipotética. ${ }^{4}$ La reconstrucción otorga un sentido que rebasa toda interpretación ortodoxa, pero que permite, sin perder rigor, exponer un sentido coherente y unitario. Finalmente, expondré la conceptuación zubiriana destacando los elementos más pertinentes para una comparación. Sólo entonces podrán compararse y evaluarse ambas doctrinas.

\section{Doctrina del cuerpo en Heidegger}

Por lo dicho, es artificial hablar de una doctrina del cuerpo en Heidegger; él no reflexionó de modo global al cuerpo. Es una intelección extrínseca al autor. Pese a ello, analizar al cuerpo como si hubiese una doctrina dará solidez y claridad. Y es que Heidegger no abordó sistemáticamente al cuerpo, pero sí consteló algunos conceptos que remiten a él: espacialidad, organismo, materia, etcétera. ${ }^{5}$ Atendiendo a este

3 Podría pensarse, de entrada, que se trata del problema mente-cuerpo; no es así o, mejor dicho, es así y no. Ambos autores buscaron reformular ese problema. Ya sea retrotrayéndose a algo previo o reformulando radicalmente lo que se entiende por cuerpo y por mente. Por principio, no pensaron al asunto en términos de "mente", sino de psique.

4 Excluyo el análisis comparativo de las acciones humanas, así como el de la determinación de la persona, como hace José Villa (2019).

5 La sola elección de los conceptos relacionados es ya una lectura particular. Ha habido varias propuestas para reconstruir al cuerpo en Heidegger. Destaco dos: la de Jaime Llorente (2015) y la de Ángel Xolocotzi (2019). Cada interpretación enfatiza cosas distintas: Llorente subraya la dimensión práctica e instrumental; Xolocotzi, la verdad y el desocultamiento. Cabe esperar resultados tan válidos como disímiles. 
"como si", será posible formular una propuesta unitaria que incluya a aquellos conceptos. ¿De qué modo?

Propongo que se divida al cuerpo en Heidegger en tres épocas. La primera estaría expuesta en Ser y tiempo, de 1927, donde inscribió a la corporalidad en la espacialización existencial; es la corporalidad ontológica. No la desarrolló, pero estableció el programa para hacerlo. Sería la época programática, la cual estaría vertebrada por el concepto de Leib. La segunda época se desarrollaría en el curso de Los conceptos fundamentales, de 1929 a 1930, pero publicado hasta 1983. En él, Heidegger se ocupó del organismo del animal. No lo estaría pensando existencial u ontológicamente, ni siquiera ónticamente, sino que estaría afianzando su programa en discusión con la ciencia. Se trataría de la época consolidativa con Organismus como concepto rector. ${ }^{6}$ Finalmente, la última época culminaría en el seminario que Heidegger impartió en la casa de Boss en 1965, pero publicada bajo el título de Seminarios de Zollikon hasta 1987. Aquí se encuentra la respuesta explícita al programa que Heidegger inauguró en Ser y tiempo — respuesta terminológica y conceptualmente rica-. Habló allí del "fenómeno del cuerpo" (Leibphänomen), "problema del cuerpo" (Leibproblem), "límites del cuerpo" Leibgrenze, "fenomenología del cuerpo" Leibesphänomenologie, etcétera. Pese a la atención que da al cuerpo en tanto que físico (Körper) y en tanto que vivo $(L e i b)^{7}$, considero que el concepto principal es el de Soma, ya que es su problematismo el que lleva a Heidegger a pronunciarse sobre el cuerpo. Sería la época resolutoria.

Las épocas del cuerpo, entonces, serían tres: la programático-corporal, la consolidativo-orgánica y la resolutorio-somática. Con base en la época y su concepto elegiré los pasajes más relevantes para delinear la reconstrucción. Se trata de una periodización mínima que propongo sólo a partir de las obras señaladas. El análisis no proviene de una revisión exhaustiva de la obra completa de Heidegger. Aun así, basta con él para presentar las líneas fundamentales del tratamiento heideggeriano del cuerpo. La investigación exhaustiva queda abierta.

6 Mi propuesta hermenéutica insistirá en lo orgánico, vínculo entre Ser y tiempo y los Seminarios de Zollikon a causa de la psique. A diferencia de la propuesta de Rodrigo Lagos (2020), no enfatizaré la dimensión conductual o impulsiva. Buscaré situar al organismo como un recurso con el cual Heidegger fue más allá de la espacialidad existencial del programa. Claro está, esto no excluye la lectura de Lagos.

7 Véase la nota 10, pues la diferenciación entre Körpery Leib conlleva problemas fenomenológicos profundos. 


\section{Época programático-corporal}

En Ser y tiempo Heidegger critica a la tradición a partir del presunto hecho de que ésta sustancializó y parcializó al hombre. Lo habría conceptuado como un alma en un cuerpo. Dice:

La persona no es ni cosa, ni sustancia, ni objeto. [...] Los actos son algo no-psíquico. [...] El ser psíquico no tiene, pues, nada que ver con el ser-persona. [...] ¿Cómo determinar ontológicamente de una manera positiva el modo de ser de la persona? [...] Lo que está en cuestión es el ser del hombre entero, ser que se concibe de ordinario como unidad de cuerpo, alma y espíritu. (Heidegger, 1997: 73)

Entonces, la psique no es lo que pensaba la tradición: una sustancia; lo psíquico no es lo determinante del ser-persona, y no lo es debido a que lo primario es "el ser del hombre entero" (dem Sein des ganzen Menschen). La integridad del hombre no es una suma de partes, es una unidad primaria. Sin embargo, su unidad no debe entenderse como individualidad, ya que el hombre es un ser respectivo, es un ser-ahí: es Da-sein. De hecho, el hombre es hombre por ser Dasein o, mejor dicho, el Dasein se entiende a sí mismo como hombre. ¿Qué es ese ser-ahí? Es un estar-en-el-mundo (In-derWelt-seins). Pero esto abre un problema: todo ente posee la estructura de estar-en-elmundo, ¿por qué es diferente el Dasein? Heidegger dice que es debido al modo de su respectividad. Esto es, es por el "estar-en" (In-Sein) del estar-en-el-mundo del Dasein que este está dado de un modo distinto. Hay que esclarecer este punto.

Heidegger distingue dos modos de estar-en. Uno tiene la forma del mero "estar dentro de" (Sein in), que compete "al ente que no tiene el modo de ser del Dasein" (Heidegger, 1997: 80). ${ }^{8}$ Pone como ejemplo al agua: ésta está dentro del vaso, está en él. Es el estar-en propio de las cosas como Körper. Es la primera modalidad de estar-en: la categorial. La segunda, la que compete al Dasein, se distingue debido a que este está en el mundo en tanto que mundo. No está en el mundo como el agua en el vaso, tampoco estaría así el alma en el cuerpo. El "en" del estar-en del Dasein, el “in" de su In-Sein, "procede de innan-, residir, habitare, quedarse en" (1997: 80). El Dasein está en el mundo habitándolo. No es mero Körper, sino que el "estar-en es, por consiguiente, la expresión existencial formal del ser del Dasein, el cual tiene la constitu-

8 Todo subrayado en las citas pertenecerá siempre al propio texto, salvo cuando esté la palabra Dasein, que subrayo en todos los casos. 
ción esencial del estar-en-el-mundo" (1997: 81). El estar-en del Dasein es existencial; es la segunda modalidad del estar-en.

El Dasein no es mero Körper, entonces, ¿no tiene espacialidad? Heidegger dice que, si bien su espacialidad se funda en la del Körper, tiene un modo propio de darse: acorde a su estar-en. El Dasein posee una "espacialidad existencial" (existenziale Räumlichkeit). Esta espacialidad es decisiva, puesto que "solo la comprensión del estar-en-el-mundo como estructura esencial del Dasein hace posible la intelección de la espacialidad existencial del Dasein" (Heidegger, 1997: 82). Por negación del consecuente, si no hay intelección de la espacialidad existencial, luego, no hay comprensión del estar-en-el-mundo del Dasein. Es en la tematización de la espacialidad existencial que Heidegger plantea la problemática del cuerpo. Dice: "De la direccionalidad provienen las direcciones fijas hacia la derecha y la izquierda. Al igual que sus des-alejaciones, el Dasein lleva constantemente consigo estas direcciones. La espacialización del Dasein en su 'corporalidad', que implica una problemática propia que no ha de ser tratada aquî" (1997: 134). La problemática del cuerpo es justo y sólo esa "espacialización del Dasein en su 'corporalidad' [Leiblichkeit]". Este es el modo de plantear el problema del cuerpo según Heidegger."

Recapitulando, el Dasein en tanto es un ser-ahí es un estar-en-el-mundo que, por cuanto es pensado como estar-en, es un estar-en existencial. El "en" del estar-en es el habitar. Por esta razón, el Dasein posee una espacialidad existencial y su espacialización es el problema de la corporalidad.

\section{Época exploratorio-orgánica}

Establecido el programa, Heidegger, en los cursos de Los conceptos fundamentales, se estaría ocupando - a la luz de una doctrina reconstruida y sólo de ella- de algo que ni es el Körper como espacialidad categorial ni es Leiblichkeit como espacialidad existencial; de un ente que ni es un mero cuerpo ni está en el mundo habitándolo: el animal. Heidegger sustentó en este texto las tesis de que "la piedra es sin mundo, el animal es pobre de mundo" y "el hombre configura mundo" (Heidegger, 2007a: 235). Sostengo que es posible erigir una correspondencia en el siguiente orden: la piedra es sin mundo, Körper, cuerpo óntico y espacialidad categorial; el Dasein configura mundo, es

9 La espacialización del Dasein abre, para Luis Flores (2003), la conexión entre el concepto de cuerpo en Heidegger y el de Merleau-Ponty. 
Leiblichkeit, cuerpo ontológico y espacialidad existencial, y el animal es pobre de mundo, Organismus y existencialmente pobre. Mas surgen varias dudas: $i$ el animal es Organismus, pero no Leib? Si lo es, ¿cómo es posible un Leib no existencial? El Leiblichkeit del Dasein, ¿es también Organismus? No habrá respuestas. ${ }^{10}$

Pienso que Heidegger, al hablar del animal, no se compromete a pronunciarse respecto a la problemática de la corporalidad. Esta libertad se constata en el hecho de que lanza hipótesis y las comprueba o deshecha sin la impronta de esclarecer lo dicho en Ser y tiempo. Esta libertad daría a Heidegger la posibilidad de enriquecer su postura inicial sin tener que pensar al Körper o al Leib. Esto no quiere decir que haya abandonado su programa, lo estaría consolidando más allá de un planteamiento fenomenológico. ${ }^{11}$ Con esto atajaría los puntos ciegos de su programa: el animal, la biología moderna, las capacidades, etcétera. Y lo haría a partir del organismo. ¿Qué es?

10 En este texto, Heidegger hablará apenas una docena de veces de Leib y Körper pero deseo llamar la atención sobre un par de cosas. Primero, estas dudas provienen de una lectura que rebasa al texto, aunque sea pertinente su formulación. Segundo, la diferencia entre Leib y Körper es, para un germanoparlante, similar a la que hay entre cuerpo vivo y cuerpo físico, aunque, de nueva cuenta, establecer sus límites representa un desafío. Tercero, Husserl se encargó de hacerlo, dirimió la diferencia - al menos en Meditaciones cartesianas - en la experiencia. El Körper es lo aprehensible; el Leib, lo aprehensible que aprehende (Husserl, 1996: $157,171,175,180-182,190)$. Heidegger, como se vio, problematiza desde un punto de vista distinto: el de la espacialización y el de la mundanidad. Animal y Dasein poseen cuerpo y están vivos, pero no están del mismo modo en el mundo. La diferencia del Leib animal y del Dasein no es inmediata ni sencilla y no la resuelve la referencia a la sensación o a la vida. Y, cuarto, el propio Heidegger encuentra penoso que el francés, con corps, no sea capaz de distinguir entre Leib y Körper. Señala que la palabra Körper proviene del corpus latino. Lo escandaloso es que Heidegger sostiene que al francés le es "más difícil ver la verdadera problemática de la fenomenología del cuerpo" (Heidegger, 2007b: 138). Por supuesto, ese señalamiento de Heidegger es extensivo al español, a la palabra cuerpo. El caso es que es falso. Es falso que, por su ascendencia latina, el corps francés o el cuerpo español tengan sólo el contenido que Körper tiene en alemán. La palabra cuerpo recubre a Leib y a Körper. Más importante aún, en español y francés hay un vocablo con enorme peso fenomenológico: carne o chair. ¿Habría que traducir Leib por 'carne’? Creo que no: la palabra carne tiene en alemán otro vocablo: Fleish. Quizá podría hablarse de Körper como cuerpo físico y de Leib como cuerpo vivo, sin embargo, Heidegger lo problematiza, como se dijo. Con Heidegger sólo podemos decir que Körper es una espacialización categorial, como la que tiene el vaso o el agua y Leib una espacialización existencial, propia del Dasein. Ese es el problema que subrayo: ¿dónde queda el cuerpo del animal? Sólo podemos afirmar que lo trató como Organismus.

11 Heidegger, al problematizar el modo en que la piedra o el animal está en el mundo, traspasa el estricto ámbito fenomenológico de la consciencia. La transponibilidad la realiza adoptando contenidos teóricos, aunque los critique. Por ejemplo, reflexiona a las moléculas. Excede dialógicamente al ámbito de la fenomenología. 


\section{Dice Heidegger:}

La tesis principal es: todo lo viviente es organismo. Todo lo viviente es en cada caso un ser vivo, y este es organismo. Ello implica al mismo tiempo que el concepto de una "sustancia viviente", de una masa viva, de una "materia vital", es un concepto contradictorio. Pues con "materia" y "sustancia" en este significado se niega justamente la organicidad de lo viviente. Lo viviente es siempre organismo. (Heidegger, 2007a: 263)

Acudiendo al texto, no es en absoluto claro por qué es contradictorio el concepto de "sustancia viviente" (lebendigen Substanz); cuanto más porque sólo lo menciona aquí. Pero, a la luz de una doctrina reconstruida, tiene total pertinencia. El organismo no es una sustancia si por ella se entiende un Körper. Lo que distingue al organismo es, de nueva cuenta, su estar-en: el modo de su respectividad. El organismo no está en el mundo como el agua en el vaso. Y así como antes se habló del ser del hombre entero, aquí cabría hablar del ser del organismo entero. Por eso dice: "La unidad de la vida no es la célula. El ser vivo pluricelular no es, como se ha supuesto, un estado celular, sino que la unidad respectiva de los unicelulares y de los pluricelulares, es decir, su específica totalidad esencial consiste en que son organismos" (Heidegger, 2007a: 263).

Inmediatamente, Heidegger define al animal con base en hipótesis que comprueba sobre la marcha. Dice: “Organismo es aquello que tiene órganos. 'Órgano' viene del

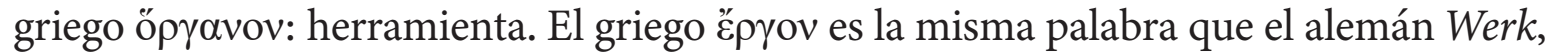
'obra'” (Heidegger, 2007a: 263). De nueva cuenta, en una lectura extrínseca, Heidegger estaría abordando el pasaje citado de Ser y tiempo, aquello de que "los actos son algo no-psíquico". Enseguida se verá por qué. La determinación del organismo recae en su actividad. El órgano, como la herramienta, tiene un para qué; además, en ambos hay un poder. El poder ver del ojo y el poder escribir de la pluma. ${ }^{12}$ Mas podemos prestar una

12 El hecho de transitar de lo animal a lo humano, en el poder escribir de la pluma, descoloca a Heidegger, quien inmediatamente corrige: "Ver y ver no son lo mismo, aunque los dos [animal y hombre] poseen ojos e incluso la construcción anatómica correspondiente" (Heidegger, 2007a: 270). Obsérvense tres cosas. Primero, Heidegger no se preocupa por ahondar en la diferencia, signo de esa libertad que - sostengo- se dio. Segundo, es un ejemplo más de cómo transita de la fenomenología a la ciencia sin que ello sea algo negativo. Y, tercero, Heidegger encuentra ya una diferencia entre "ver y ver" del animal y el hombre, razón por la cual el problema del organismo supone un aspecto más allá de la experiencia o sensación: la sensación en el animal y el hombre son distintas. Distanciándose de la fenomenología husserliana. 
pluma para que otro escriba; un ojo, no. Éste está a nuestro alcance por sí mismo. "El órgano es una herramienta incorporada [eingebautes] en el que la emplea" (2007a: 270). Aquí Heidegger explora lo más relevante del órgano: la capacidad. La pluma, por ella misma, no tiene la capacidad de escribir, pero "el órgano tampoco tiene por sí mismo la capacidad de ver" (2007a: 272). Las capacidades les pertenecen a los órganos "pero justamente como órganos, es decir, como pertenecientes al organismo" (2007a: 272). Ahondando en la capacidad, Heidegger defiende una posición enigmática: los órganos no tienen capacidades, "las capacidades tienen órganos" (2007a: 273). Y formula luego otra tesis aún más enigmática: "El órgano queda comprendido en la capacidad de tocar y moverse, y solo esta puede retomarlo y destruirlo" (2007a: 276).

La lectura obvia sería la de reparar en la preminencia de la posibilidad en la propuesta heideggeriana. Lectura legítima, pero creo que hay otra que no entra en conflicto con la anterior. Antes evoqué a lo psíquico, fue por lo siguiente: Heidegger estaría reformulando el problema clásico de las facultades del alma. ${ }^{13}$ Dado que la actividad no es psíquica, sino del organismo entero, ¿qué decir de la facultad? Heidegger estaría problematizando - deliberadamente o no- la presunta índole psíquica de la actividad para situarla en la capacidad del ser vivo como organismo unitario. Como dije, el problema del Körper, la psique y la facultad no derivan del texto, pese a que interrogar por ellos sea legítimo. No obstante, en ellos está el enlace a la respuesta definitiva.

\section{Época resolutorio-somática}

Después de treintaiocho años y del fructífero rodeo del organismo, Heidegger enriqueció terminológica y conceptualmente su análisis del cuerpo. Ya está en condiciones de responder a su programa ontológico. Lo hizo, como dije, en el seminario que dictó en la casa de Boss. Es revelador que su respuesta provenga de las insistentes preguntas de su auditorio, en el cual había psiquiatras. A ellos les preocupaba el tema

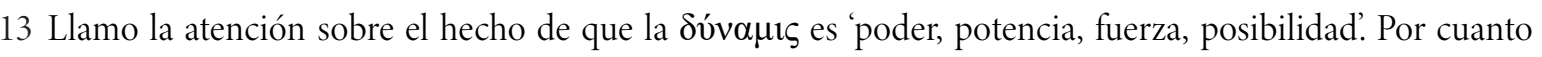

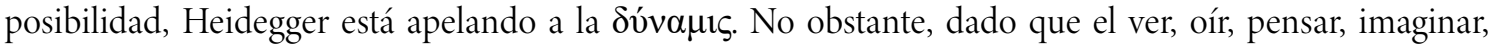

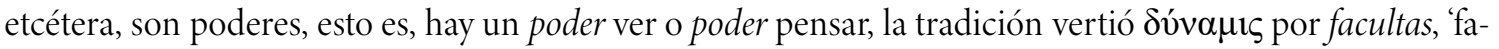
cultad'. En estos términos, Heidegger, en su negativa a admitir la dualidad cuerpo-alma -a la cual se le adjudicó tradicionalmente una segunda dualidad, la del sentir-inteligir - se vería en la necesidad de reformular

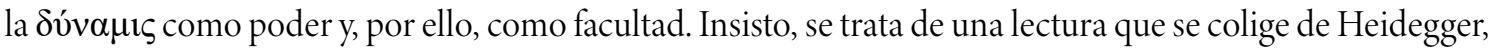
no está presente en él. 
de la psique y no se conformaron con su eliminación por sustancial o tradicional, tampoco admitieron respuestas laxas sobre el cuerpo.

En ese contexto, dice Heidegger: "Excluimos la pregunta que ante todo los inquieta, la de lo psicosomático, la de cómo debe ser determinado. Me gustaría ahora, no para eliminar esa inquietud, sino para incrementarla, abordar esta noche el llamado problema del cuerpo y con esto, a la vez, la pregunta de la psicosomática" (Heidegger, 2007b: 121). El "problema del cuerpo" (Leibproblem) implica por él mismo la respuesta a la psicosomática (Psychosomatik), ya que "en la psicosomática se trata del ser-humano del ser humano (das Menschsein des Menschen)" (2007b: 122). La unidad íntegra del ser humano apunta al problema del cuerpo, del cual la psicosomática es extensiva. Esto debe subrayarse: la psicosomática está sólo implicada, no desarrollada. Heidegger es renuente a pensar a la psicosomática. ¿Por qué? Porque hay una circularidad metodológica. ${ }^{14}$ ¿Cómo se accede al soma?: desde el soma, ¿y cómo, a la psique?: desde la psique. Todavía más, pensar en términos de psique y de soma, tiene la impronta de hacernos cuestión de lo más espinoso del asunto: la conexión entre psique y soma. Porque si se piensa a lo psicosomático desde la psique, se omite al soma. Es lo que hace quien describe una experiencia estética, por ejemplo. Mientras que, si se piensa desde el soma, se omite a la psique. Es lo que hace el científico al mensurar; obvia a lo psíquico. Por eso dice: “¿Son las conexiones entre psique y soma algo psíquico o algo somático o ni uno ni otro? Este callejón sin salida, al que hemos llegado, les muestra mejor que cualquier otra cosa qué tan esencial es la cuestión del método" (2007b: 126). La psicosomática nos deja en un "callejón sin salida". Por esta razón, hay que acudir, por cuanto es más radical y por cuanto no es "ni uno ni otro", al problema del cuerpo. Ese es el modo metodológico viable para plantear la cuestión.

Es entonces que Heidegger busca, explícitamente, responder al programa de Ser y tiempo; esto es, problematizar al cuerpo como espacialización existencial. Dice: "El Dasein del ser humano es espacial en sí, en el sentido de instalar el espacio y de la espacialización del Dasein en su corporalidad. El Dasein no es espacial porque sea corporal, sino que la corporalidad solamente es posible porque el Dasein es espacial en el sentido de instalador" (Heidegger, 2007b: 127). Respuesta insatisfactoria para

14 Dice Heidegger: "Nos movemos en un círculo. Sin embargo, este círculo no es un circulus vitiosus, un círculo 'erróneo", puesto que depende del método. Dice inmediatamente: "La pregunta por lo psicosomático es, en primera línea, una cuestión de método" (Heidegger, 2007b: 125). 
los asistentes y para el propio Heidegger, quien la extiende enfatizando una diferencia asaz problemática: la diferencia entre Körper y Leib. La piensa del siguiente modo:

El cuerpo [Leib] participa siempre de este respectivo estar-aquí, ¿pero cómo? ¿El estar-aquí está determinado por el volumen de mi cuerpo [Körpers]? ¿Coinciden los límites de mi cuerpo [Körpers] y de mi cuerpo? [Leib]. [...] Quizás uno podría acercarse más al fenómeno del cuerpo [Leibphänomen] mediante un diferenciar los diversos límites entre cuerpo [Körper] y cuerpo [Leib]. (2007b: 133)

Heidegger pone un ejemplo: al señalar un crucero, el "límite del cuerpo" como Körper (Körpergrenze) estaría en la punta del dedo, sin embargo, el "límite del cuerpo" como Leib (Leibgrenze), ¿hasta dónde estaría dado ${ }^{15}$ Con razón de este problema, Heidegger dice lo más esclarecedor sobre su idea de cuerpo:

¿Está el cuerpo [Leib] en el "yo" o está el “yo" en el cuerpo [Leib]? En todo caso, el cuerpo [Leib] no es una cosa, un cuerpo [Körper], sino que todo cuerpo [Leib], esto es, el cuerpo en cuanto cuerpo [Leib als Leib], es en cada caso mi cuerpo [Leib]. El corporar del cuerpo [Leiben des Leibes] se determina a partir del modo de mi ser. El corporar del cuerpo es así un modo del Dasein. (2007b: 134)

El "corporar del cuerpo" es la respuesta definitiva al problema de la espacialización existencial. El cual es un corporar que "está codeterminado [mitbestimmt] por mi ser-humano" (2007b: 134). Por esta razón, toda actividad humana sin excepción corpora. Ya sea en el habla, en el pensar o en los estados de ánimo, hay siempre e irreductiblemente un corporar codeterminado como estructura del estar-en-el-mundo del Dasein. En los estados de ánimo, este corporar supone al otro; por ejemplo, en el ruborizarse frente a él, supone su presencia.

Respuesta que, pese a su importancia, volvió a dejar insatisfechos a los asistentes, quienes advirtieron que Heidegger eludió el problema de la psicosomática. Heidegger seguirá renuente a pensar en los términos de una psicosomática, pues su formulación implica adoptar una actitud teórica - para mensurar-o, por ejemplo, estética. El corporar es más radical; es estructural. Nuevamente, el corporar implica a la psicosomática y, por ello, a la ciencia y a toda actitud. Dice:

15 Ángel Xolocotzi (2019) ve en esta diferencia de límites al ocultamiento y desocultamiento del cuerpo. Habría un errar, si se toma al Körper, y un misterio, si al Leib. 
El fenómeno del cuerpo [Leibphänomen] solo puede ser mirado si en la superación crítica de la relación sujeto-objeto, válida hasta ahora, el ser-en-el-mundo es experienciado propiamente y asumido y soportado propiamente como rasgo fundamental del Dasein humano. [...] Debe verse que la ciencia como tal, que el conocimiento teórico-científico como tal, es un modo fundado del ser-en-elmundo, se funda en el tener corporal de mundo. (Heidegger, 2007b: 143)

Sumariamente, la doctrina del cuerpo en Heidegger tendría estos tres momentos: el delineamiento de la espacialización existencial, el rodeo del organismo y la respuesta definitiva a la problemática del cuerpo como un corporar codeterminado constitutivo al Dasein en tanto que está-en-el-mundo, con inclusión del otro y como fundamento de toda actitud.

\section{Conceptuación zubiriana}

La conceptuación zubiriana no precisa de reconstrucción: Zubiri la expone monográficamente en su artículo sobre el cuerpo. No obstante, la complicación reside en lo apretadas que son sus tesis. Es necesario recurrir a otros textos para exponerlas con la debida claridad. ${ }^{16}$ Para avanzar sobre lo ya ganado, como para delinear la comparación, partiré de ciertas correspondencias conceptuales entre Heidegger y Zubiri en lo concerniente al cuerpo. Subrayo "correspondencias", ya que, como se comprobará enseguida, ambos autores parten de métodos distintos y, como dije antes, hasta opuestos. ${ }^{17}$ Tomo tres correspondencias.

Primero, Heidegger se interroga por el ser, el Sein, para exponer al Dasein; Zubiri, por la realidad, desde la cual expone a la realidad humana como sustantividad. Segundo, Heidegger argumentó en contra de toda posibilidad de abordar a la psicosomática en sus términos; Zubiri, en cambio, se apropia de ella reformulándola

16 Son tesis apretadas debido a que en ellas culminan varias décadas de reflexión exclusiva al cuerpo, como bien señalan Paula Ascorra et al. (2001).

17 Antes mencioné que Heidegger parte de la ontología; Zubiri, de la metafísica. Sin ahondar en la diferencia, sólo señalaré cómo las entendió cada autor. Para Heidegger, resume Ricardo Guerra (1996): "es esta historia de la metafísica [como historia del Ente Supremo], en tanto que determinación del Ser como Ser o fundamento de los entes, lo que hace posible el tránsito a la ontología fundamental [...] como la descripción y comprensión del Ser del Dasein" (12). Por otro lado, para Zubiri, como resume José Villa (2019): "la filosofía primera, como estudio de la realidad en tanto algo en propio, debe ser llamada metafísica; [...] Y dado que el ser es el modo como lo real se hace presente en el mundo, la ontología es un derivado de la metafísica" (70). 
y tomándola como el modo propio de conceptuar a la unidad humana. Y, tercero, Heidegger distingue al cuerpo del Dasein por estar en el mundo en tanto que mundo; Zubiri señala que el hombre está abierto al mundo, entre otras cosas, desde su constitución filogenética. Sólo tras la clarificación de estas correspondencias se podrá exponer la doctrina zubiriana del cuerpo. Hay que dar cuenta de la constructividad, la sustantividad y la psique antes de interrogar por el cuerpo. Reitero que no incluiré el análisis de las acciones o de la persona. ${ }^{18}$

\section{La constructividad}

Zubiri, como Heidegger, parte de la unidad del hombre; en este caso, de la unidad de la realidad humana. Sin embargo, Zubiri se cuestiona por el modo en que esa unidad está dada. Dice al comienzo de su artículo: "El hombre es una realidad una y única: es unidad. No es unión de dos realidades, lo que suele llamarse 'alma' y 'cuerpo'. Ambas expresiones son inadecuadas porque lo que con ellas pretende designarse depende esencialmente de la manera como se entienda la unidad de la realidad humana" (Zubiri, 1974: 479). Zubiri se inspira en las lenguas semíticas, donde existe el "estado constructo", el cual señala a un "de". ${ }^{19}$ Este "de" está dado en una unidad. Es decir, el “de" se da en un "en” o, mejor dicho: "el 'de' está construido según el 'en”" (Zubiri, 2008: 356).

18 Pese a que no es una reconstrucción, lo cierto es que la elección de estos temas sigue siendo un enfoque. Llamo la atención sobre el hecho de que, así como Xolocotzi (2019) insistió en la relación cuerpo-verdad en el desocultamiento, así, en Zubiri existe un enfoque similar: el de la respectividad cuerpo-verdad en la actualización. Valentina Bulo (2009) detalla esa respectividad.

19 El estado constructo señala al caso gramatical genitivo que, en español, se expresa con la preposición "de". Por ejemplo, en el "vaso de vidrio". Es posible decir también "el vaso de Juan", pero ese es un caso posesivo. El estado constructo implica a ambos. En árabe, por ejemplo, la frase "كوب الزجاج" (kub alzujaj) se traduce como "el vaso es de vidrio". Pero una traducción literal sería: "vaso el-vidrio". Se ha omitido el rodeo de la preposición y del ser. La conexión de las cosas es directa: no hay una relación entre sujeto y predicado, sino entre dos sustantivos, donde uno funciona como absoluto y otro como relativo. El estado constructo "expresa las cosas conexas mediante nombres morfológicamente construidos unos sobre otros" (Zubiri, 2008: 354). Así es como Zubiri evita el sustancialismo: su propuesta se basa en la conexión intrínseca de las cosas, la cual no está dicha en términos de sustancialidad o subjetualidad, sino de sistematicidad. El realismo sistematista - como lo llama Fernando Ortiz (2019b) - "es la apuesta por dejar de considerar a la realidad como un conjunto de cosas independientes, para considerarlas sistemáticamente, esto es, de tal modo que no se pueda entender una sin entender a las demás” (77). Zubiri se ajusta a esta caracterización. 
A partir de esto, dice:

Las cosas reales están constituidas por "notas". Tomo el vocablo en su acepción más lata [...]. Cada una de estas notas está con las demás en una forma muy precisa: es nota "de" las demás. [...] Cuando hic et nunc es nota de esta cosa real, está integrada a ella. Y estar integrada significa que no es un algo meramente añadido a las demás notas sino que la nueva nota cobra el carácter del "de" constitutivo de la cosa real. Por tanto, no hay "nota + de" sino "nota-de". (Zubiri, 1974: 479)

La constructividad intrínseca de lo real está dada en la unidad de las cosas como "notas-de", las cuales se construyen unas sobre otras. Por ejemplo, en el vaso de vidrio, este es vaso-de vidrio y vidrio-de vaso. Hay una codeterminación mutua. ${ }^{20}$ En el caso del hombre, hay más notas implicadas. Hay sustancias: glucosa, calcio, proteínas; partes: venas, huesos, ojos; cualidades: albinismo, peso, talla. En suma, todo cuanto pueda mentarse del cuerpo. En todos los casos, estas notas también son "notas-de" y, por tanto, están construidas sobre las demás. Es el organismo como sistema. En el albinismo, a nivel fenotípico y genotípico, están presentes todas las notas orgánicas. Algunas tendrán mayor predominancia que otras, pero participan todas.

Sin embargo, cada nota es, por sí misma, insustantiva, dado que la sustantividad es sólo del sistema entero. Por esta razón puede haber sustancias insustantivas. Dice Zubiri (2001): "Sustantividad no hay más que una: la de mi ser vivo" (58). Y dice luego algo que recuerda a Heidegger: "El ser vivo no es una sustancia más, ya que está caracterizado por algo constitutivamente funcional; por eso no es una sustancia más como puede ser el ácido clorhídrico respecto de los componentes que posee" (2001: 58-59). Zubiri detalla por qué no es sustancial, dice: "Estoy yo por encima de mi naturaleza. No soy sub-stante sino supra-stante. [...] Hay que decir de toda sustancia, de toda realidad, que su momento de sustantividad es anterior e intrínsecamente fundante respecto de su momento de subjetualidad o de sustancialidad" (2001: 59). Entonces, la sustantividad está construida por "notas-de", no se identifica con la sustancia y es más bien un sistema que dota de unidad a aquellas notas. ¿Cómo esa dotación? Se dijo antes: las notas se construyen según el "en". Esto es, la constructividad intrínseca de la cosa real "no se trata de la in-herencia de unas notas a un sujeto sino de la co-herencia de las notas entre sî" (Zubiri, 2001: 64). Por esto, "la unidad de este

20 La constructividad supone a la codeterminación y a la respectividad. Sin embargo, Zubiri los emplea en muchos sentidos. Fernando Ortiz (2019a) recoge varios de éstos. 
sistema [...] está presente en cada una de las notas" (2001: 64). De este modo, Zubiri tematiza el modo en que está dada la unidad del hombre: como unidad sistemática y sustantiva dada en constructividad coherencial.

\section{Lo psicosomático}

Las sustancias, partes y cualidades son las notas que constituyen al organismo como sistema. Son notas orgánicas o, estrictamente, fisicoquímicas. No obstante, existen otras notas que no se reducen al organismo: la volición, el logos, la inteligencia, etcétera. Éstas son notas psíquicas.

El organismo es un sistema, pero no es el sistema sustantivo; éste es sólo la sustantividad humana. Y así como la nota se mostró como insustantiva por el sistema orgánico, de igual modo, el organismo se muestra como insustantivo por la sustantividad humana. El organismo no es una sustancia, pero tampoco es lo sustantivo, "es tan solo un subsistema parcial dentro del sistema total de la sustantividad humana" (Zubiri, 1974: 481). Lo mismo sucede con la psique: es otro subsistema parcial. El siguiente paso es fundamental. Estos subsistemas, como las notas, también son constructos: son organismo-de y psique-de. Toda nota fisicoquímica o psíquica está construida sobre las demás. Dice Zubiri (1974): “Cada una de las notas psíquicas son 'de’ las notas orgánicas, y cada una de las notas orgánicas es nota 'de' las notas psíquicas” (481). Es decir, aquí y ahora, la glucosa, los músculos, el calcio, etcétera, están construidos en unidad sistemática en, por ejemplo, el acto de recordar. Y, a la inversa, la memoria como nota psíquica, como memoria-de, codetermina a la glucosa, al músculo, etcétera. Piénsese, por ejemplo, en la memoria muscular: echa mano de todas las notas. Aunque, como antes, a unas con mayor preponderancia que otras. Pues bien, lo mismo sucede en todo acto humano.

Si se toma, no ya a las notas, sino a los subsistemas como tales, estos se codeterminan del siguiente modo. En tanto que el organismo es organismo-de la psique, el "de" tiene "una precisa estructura: es corporización de la psique". Y en tanto la psique es psique-del organismo, el "de" es "animación del cuerpo" (Zubiri, 1986: 462). Esto supone que "la psique es desde sí misma orgánica y el organismo es desde sí mismo psíquico" (Zubiri, 1974: 481). Zubiri es más contundente en Sobre el hombre. Dice: “Todo lo psíquico es corpóreo; y todo lo corpóreo es psíquico" (Zubiri, 1986: 456). La sustantividad humana es, entonces, una psique orgánica o un organismo psíquico. 
En definitiva, es la unidad de lo psicorgánico. Este modo constructo de conceptuar al hombre permitió a Zubiri plantear una de sus tesis más importantes. La inteligencia y la sensibilidad no son facultades opuestas o siquiera separadas, sino que la inteligencia es inteligencia sentiente y la sensibilidad es sensibilidad intelectiva. Dice Zubiri (1986): "En la medida que el sentir humano tiene esta alteridad [la del 'de suyo'], esta formalidad de realidad, es un sentir no puro o animal, sino un sentir intelectivo. La inteligencia humana es constitutiva y formalmente sentiente. Esta intelección sentiente es lo que constituye el carácter estructural de todo lo psíquico" (458-459). ${ }^{21}$ Con lo cual está dicho ya qué es lo psíquico, lo orgánico y lo psicorgánico para Zubiri.

Situado en la unidad psicorgánica, Zubiri delimita tres momentos: el de organización, solidaridad y corporeidad. La organización indica a la actividad unitaria de lo orgánico y lo psíquico; la solidaridad, a la interdependencia entre notas o subsistemas, y la corporeidad, al momento donde la unidad psicorgánica se corporiza desde ella misma. Esta corporización se funda en los otros dos momentos, pero al mismo tiempo, en ella está la fundamentación de lo orgánico mismo, como ya se verá. Por el momento, baste con decir que la corporeidad y la vida tienen la siguiente relación: “Toda vida es actualidad 'física' en corporeidad y toda corporeidad, toda presencialidad 'física' es de carácter vivo [...]. El carácter vivo cualifica la corporeidad en fenómenos tales como la 'expresión', la corporeidad es, entre otras cosas, expresión de la vida" (Zubiri, 1974: 483). Luego de pensar la unidad sustantiva del hombre, Zubiri ya está en condiciones de decir qué es el cuerpo en tanto que tal. Esto es, como lo orgánico de la unidad psicorgánica.

\section{El cuerpo}

Abordar al cuerpo desde la sustantividad implica desgajar los momentos de lo psicorgánico - organización, solidaridad y corporeidad- en el organismo. En este, se expresan como funciones: la organizadora, configuradora y somática. La definición del cuerpo está en el despliegue de estas funciones.

La función organizadora "es la contribución de las notas fisicoquímicas a la organización del sistema total” (Zubiri, 1974: 485). El organismo no reside en las notas

21 Como señala Marco García, "Zubiri ha desplazado el problema de la relación entre lo mental y lo corporal a la concurrencia entre los diferentes estados psico-orgánicos en los que el hombre se encuentra en el mundo, es decir a las actualizaciones corpóreas en el mundo" (2015: 603). 
fisicoquímicas o, siquiera, en los órganos, sino en la organización misma del sistema. Esta función es solamente contributiva. La función configuradora es "en la que cada parte está conectada en cierto orden a las demás. Esta unidad de ordenación es una 'figura' (dinámica, bien entendido)" (1974: 485). Sostengo que esta "figura" —que no "forma"- estaría relacionada con lo que, más adelante, Zubiri llamó phylum. ${ }^{22} \mathrm{La}$ figura estaría apuntando a la dimensión filética. Finalmente, la función somática es el "momento de corporeidad, esto es, un momento de actualidad, de presencialidad 'física' en la realidad" (1974: 485). Estas tres funciones son estrictamente materiales; refieren a las notas fisicoquímicas del subsistema orgánico. No obstante, la materialidad propia de la función somática precisa de mayor revisión.

La materialidad somática es, en cierto sentido, distinta de la materialidad orgánica. Es decir: "El organismo tiene aquí una función propia: la de ser el fundamento material de esta actualidad presencial. La materia como fundamento de actualidad, de presencialidad 'física' es lo que debe llamarse soma" (Zubiri, 1974: 485). El organismo es el fundamento material de la sustantividad humana, pero, dentro de él, la función somática es la materialidad qua materialidad. En palabras de Zubiri (1974):

Ser soma, ser cuerpo no es formalmente idéntico a ser organización físico-química. Es sin embargo una función estrictamente material: es, si se quiere, materia somática a diferencia de materia orgánica. La primera concierne al organismo como fundamento de actualidad, la segunda le concierne como fundamento de organización. (485)

Soma y organismo no son lo mismo, hay una diferencia analítica. Y es debido a que la materia somática es la presencialidad de la cual la función somática es fundante. Por supuesto, es fundante, pero sólo en un sentido estructural, pues dicha función "de hecho, presupone la función organizadora y la de configuración; sin estas funciones no habría presencialidad física. Pero no se identifican formalmente con esta. [...] Es [la función somática] sin embargo una función estrictamente material" (Zubiri, 1974: 485). Por todo lo dicho, la función somática es la fundamentación material, donde se efectúa la actualidad presencial, física y viva.

22 Sobre ello dice, pensando a la dimensión social del hombre: "El carácter genético pertenece intrínseca y formalmente, no solo causalmente, a la convivencia. Es formalmente una convivencia de generantes y generados en cuanto generantes y en cuanto generados. Esto es, es una convivencia de índole filética: es convivencia de un mismo phylum, de una misma especie" (Zubiri, 2006: 39-40). 
Sumariamente, Zubiri partió de la constructividad para sostener que la sustantividad es un sistema de notas-de. En la sustantividad humana, las notas son de dos tipos: las fisicoquímicas y las psíquicas. Las primeras construyen al organismo; las segundas, a la psique. Organismo y psique son los dos subsistemas parciales de la sustantividad humana en tanto que psicorgánica. Lo psicorgánico posee tres momentos -organización, solidaridad y corporeidad - que se desgajan en el organismo como tres funciones - organizadora, configuradora y somática-. La función somática revela la diferencia entre materia orgánica y materia somática. Esta última es la actualidad presencial, física y viva de la sustantividad humana.

\section{Conclusiones}

Recordando que la doctrina heideggeriana del cuerpo es una doctrina reconstruida y que la zubiriana es una doctrina temática y unitaria, la comparación entre ambas sucede en varios niveles: en las similitudes, en las diferencias y en su evaluación.

Similitudes. 1: Sendos autores partieron de una misma directriz: no sustancializar al cuerpo, al alma o al ser humano. Sostuvieron que el abordaje del cuerpo debe hacerse desde la unidad íntegra del ser humano. Heidegger partió del ser del ser-humano; Zubiri, de la sustantividad humana. 2: Ambos autores se interesaron en lo corporal por cuanto implica una cierta concreción. Heidegger lo planteó en términos de espacialidad existencial; Zubiri, como momento de actualidad presencial y física. 3: Los dos autores determinaron al cuerpo desde una cierta congeneridad. Heidegger definió al corporar del cuerpo como un corporar codeterminado fundado en el estaren-el-mundo del Dasein; Zubiri, como la corporización del sistema constructo que, al ser inteligencia sentiente, está abierto al mundo como realidad en tanto que realidad. En líneas generales, uno y otro autor tuvieron un planteamiento similar.

A partir de este planteamiento, existieron otras coincidencias derivadas. Ambos se ocuparon del cuerpo preocupados por distinguirlo del del animal. Heidegger sostuvo la tesis de la pobreza del mundo del animal frente a la configuración de mundo del Dasein; Zubiri diferencia entre la formalidad de estimulidad del animal y la formalidad de realidad del hombre. Ambos utilizaron una terminología similar. HeideggerhablódecuerpocomoKörperyLeib, organismo(Organismus)ysoma(Soma); Zubiri, de corporeidad, organismo y soma. Ambos tuvieron como elemento problemático a lo psicosomático. Heidegger lo implica en el corporar codeterminado; 
Zubiri lo reformula en la unidad constructa. Ambos pensaron al gesto. Heidegger, pensó al gesto como corporar de un estado de ánimo; Zubiri, como expresividad corporal de la vida. Finalmente, ambos buscaron la inclusión del otro. Heidegger lo incluye en la codeterminación; Zubiri, en la versión filética como dimensión social.

Diferencias. 1: En el organismo: Heidegger insistió en el carácter de herramienta del órgano; Zubiri, en el carácter organizativo. 2: En la psique: Heidegger descarta su abordaje metodológico por sustancializar o dualizar; Zubiri descarta ese abordaje, pero la reformula como subsistema para corporizarla. 3: En el mundo: Heidegger lo emparentó con el habitar y lo existencial; Zubiri, con la formalidad de realidad y la inteligencia sentiente. 4: En el acceso al mundo: Heidegger sostiene la apertura del Dasein por la comprensión; Zubiri, por la sensibilidad intelectiva.

Vistas las similitudes y diferencias, es posible formular una evaluación entre ambas doctrinas. Sabiendo que la de Heidegger está reconstruida, es posible contrastarla, no integralmente, sino en aspectos específicos presentes en su obra. Sólo así puede ser una evaluación justa.

Evaluación. Primero: Al implicar a lo psicosomático en el corporar del cuerpo, Heidegger declara la unidad psique-soma, pero no la demuestra. Más aún, parece declararla como insoluble. En contra, Zubiri sí buscó detallar la conexión de modo exhaustivo. Segundo: Heidegger refiere a la codeterminación, pero no la detalla. De allí la dificultad de distinguir al cuerpo animal del del Dasein. En contra, Zubiri llevó hasta sus últimas consecuencias y en diversas dimensiones su idea de constructividad, anclando en ella la diferencia del hombre respecto del animal. Tercero: En Heidegger, la relación problemática entre Organismus y Leib es una relación extrínseca a sus textos, pero la relación entre Leib y Körper sí la abordó de modo específico. En uno u otro caso, no es claro cómo se relacionan. En contra, Zubiri articuló sus conceptos de modo coherente y exhaustivo, distinguiendo, incluso, entre materia orgánica y materia somática. Cuarto: Pese a que Heidegger los menciona, no ahonda en conceptos tales como incorporar, materia, especie o sensibilidad; Zubiri sí, por lo cual, puede decirse que los conceptos zubirianos son más efectivos. Quinto: Heidegger abundó en qué es el órgano; Zubiri no. Sexto: Heidegger planteó el problema de los límites del cuerpo como Leib y como Körper; Zubiri no. Por lo dicho, puede concluirse que la doctrina zubiriana es más exitosa. Naturalmente, lo es de un modo integral, pues la suya es una doctrina temática; pero también puede decirse que es más exitosa en aspectos específicos tratados por ambos autores. 
Hecha esta evaluación entre sendos autores, es posible señalar, además, algunos aspectos que los dos obviaron. Los dos señalaron el tema de la vida como esencial - Heidegger, en la determinación del organismo; Zubiri, en la corporeidad-, sin embargo, ninguno incluyó a la vida como un elemento argumental central; sólo lo declararon. Por otra parte, pese a que ambos partieron de una idea similar de respectividad, no precisaron qué es la respectividad viva o el modo de ser vivo a diferencia de cualquier otro. Partieron de una unidad sin haberla clarificado. Finalmente, ninguno de los dos autores incluyó en su definición última de cuerpo a la carne. El problema de la carne viva, de la mera carne o de la encarnación son elementos que obviaron en su definición última (sin que ello implique que no la hayan abordado en otros escritos). Los elementos señalados, junto con los enfoques que salieron al paso, pero que no se abordaron — verdad, acción o persona-, además de ajenos a la comparación Heidegger-Zubiri - el cuerpo vivido en Merleau-Ponty y el cuerpo sexuado en Sartre-, son los materiales mínimos para la elaboración de un concepto de cuerpo completa.

\section{Referencias bibliográficas}

Ascorra, Paula; Espinoza, Ricardo. (2001). "Un cuerpo y alma en Zubiri... Un problema filosófico-teológico". Pensamiento, 67(254), 1061-1075. https://revistas.comillas. edu/index.php/pensamiento/article/view/1581

Bulo Vargas, Valentina. (2009). "Verdad del cuerpo en Xavier Zubiri”. Revista Portuguesa de Filosofía, 65, 965-974. https://www.jstor.org/stable/41220910

Flores, Luis. (2003). "Fenomenología de la espacialidad en el horizonte de la corporalidad”. Teología y Vida, 44(2-3), 265-269. http://dx.doi.org/10.4067/S004934492003000200011

HeIDEgGer, Martin. (1977). Sein und Zeit. Vittorio Klostermann.

Heidegger, Martin. (1983). Die Grundbegriffe der Metaphysik. Welt - Enlichkeit Ensmankeit. Vittorio Klostermann.

Heidegger, Martin. (1987). Zollikoner Seminare. Protokolle - Zwiegesprachë - Birefe. Vittorio Klostermann.

HeIdegger, Martin. (1997 [1927]). Ser y tiempo (Jorge Rivera, Ed.). Editorial Universitaria. 
Heidegger, Martin. (2007a [1983]). Los conceptos fundamentales de la metafísica. Mundo, finitud, soledad (Alberto Ciria, Ed.). Alianza.

HeIdegger, Martin. (2007b [1987]). Seminarios de Zollikon (Ángel Xolocotzi. Ed.). Morelia Editorial.

Husserl, Edmund. (1996 [1931]). Meditaciones cartesianas (José Gaos y Miguel García Baró, Eds.). Fondo de Cultura Económica.

García Sierra, Marco Antonio. (2015). “Análisis metafísico-noológico de la corporeidad desde el pensamiento de Xavier Zubiri: la apertura corporal”. Thémata. Revista de Filosofía, (46), 599-606. https://revistascientificas.us.es/index.php/themata/ article/view/433

Guerra, Ricardo. (1996). “Ontología y Metafísica”. Theoría. Revista del Colegio de Filosofía, (3), 11-24. https://doi.org/10.22201/ffyl.16656415p.1996.3.143

Lagos Berríos, Rodrigo. (2020). "Heidegger y la cuestión del cuerpo en Ser y tiempo: Buscando el lugar del cuerpo en la analítica existencial del Dasein”. Límite. Revista Interdisciplinaria de Filosofía y Psicología, 15(3), 1-16. http://dx.doi.org/10.4067/ s0718-50652020000100203

LlORENTE, Jaime. (2015). “Heidegger y el estatuto ontológico del cuerpo. Una confrontación con la fenomenología de la carnalidad de Michel Henry”. Ideas y Valores, 65(162), 261-289. http://dx.doi.org/10.15446/ideasyvalores.v65n162.48418

Ortiz Santana, Fernando Esaú. (2019a). "El problema de las categorías en la filosofía de Xavier Zubiri”. En Alfonso Villa (Coord.), El realismo de Xavier Zubiri en el horizonte del siglo XXI. Itaca.

Ortiz SANTANA, Fernando Esaú. (2019b). "Principios para un realismo post-creacionista”. Open Insight, 11(21), 61-85.

SARTRE, Jean-Paul. (1993 [1943]). El ser y la nada: Ensayo de ontología fenomenológica (Juan Valmar, Ed. ). Atalaya.

Villa SÁnchez, José Alonso. (2019). “Estructura radical de la realidad humana en Xavier Zubiri”. Mutatis Mutandis: Revista Internacional de Filosofía, 1(12), 67-89. https:// revistamutatismutandis.com/index.php/mutatismutandis/article/view/123

Xolocotzi, Ángel. (2019). “La verdad del cuerpo. Heidegger y la ambigüedad de lo corporal”. Estudios de Filosofía, (61), 125-144. https://doi.org/10.17533/udea.efn61a09 
Zubiri, Xavier. (1974). “Respectividad de lo real”. SALESIANUM, 36(3), 479-486.

ZuBiri, Xavier. (1986). Sobre el hombre. Alianza.

Zubiri, Xavier. (2001). Sobre la realidad. Alianza.

Zubiri, Xavier. (2006). Tres dimensiones del ser humano. Individual, social, histórica. Alianza.

Zubiri, Xavier. (2008). Sobre la esencia. Alianza. 